\title{
Transcriptional Activity of Aerobic and Anaerobic Ammonia-Oxidizing community in the Intertidal Sponge Cinachyrella Australiensis, Ambient Seawater, and Sediment
}

Guofang Feng ( $\nabla$ fenggf@szpt.edu.cn )

Shenzhen Polytechnic https://orcid.org/0000-0001-7109-1139

Shaofeng Li

Shenzhen Polytechnic

Lijuan Zhang

Peking University Shenzhen Graduate School

Huchun Tao

Peking University Shenzhen Graduate School

\section{Research Article}

Keywords: Sponge, Ammonia oxidation, amoA, hzsB, Functional transcript, qPCR assays

Posted Date: April 8th, 2021

DOI: https://doi.org/10.21203/rs.3.rs-382482/v1

License: (c) (1) This work is licensed under a Creative Commons Attribution 4.0 International License.

Read Full License 


\section{Abstract}

Microbial ammonia oxidation plays a central role in nitrogen cycling. Hitherto, four types of autotrophic ammonia-oxidizing microorganisms are identified, including aerobic ammonia-oxidizing archaea (AOA), aerobic partial-nitrification ammonia-oxidizing bacteria (parAOB), aerobic complete-nitrification $A O B$ (comAOB), and anaerobic $A O B$ (AnAOB). However, revelation and comparison of the active ammoniaoxidizing community in the marine sponges and their ambient environments is scarce. Here, transcribed ammonia oxidation phylomarker gene amoA of $\mathrm{AOA}$, parAOB, and comAOB and $h z s B$ of AnAOB were amplified to investigate the active ammonia-oxidizing populations in a representative marine sponge Cinachyrella australiensis, ambient seawater, and sediment niches. Ammonia-oxidizing population in $C$. australiensis consists of $A O A$, parAOB, and $A n A O B$, significantly different from that in seawaters comprising of $\mathrm{AOA}$ and in sediments containing $\mathrm{AOA}$, parAOB, comAOB, and $\mathrm{AnAOB}$. The quantitative assay demonstrates that $\mathrm{AOA}$ amoA transcripts are exclusively detectable or higher in abundance than parAOB amoA, comAOB amoA, or AnAOB hzsB transcripts by orders of magnitude in $C$. australiensis, seawater, and sediment niches. This transcript-based analysis clarifies the remarkable niche differentiation of putatively active ammonia-oxidizing microbiota in $C$. australiensis and the ambient environments. Such a work further contributes to the understanding of in situ active ecological functions of sponge microsymbionts in nitrogen cycling.

\section{Introduction}

Ammonia oxidizing prokaryotes (AOP) play a fundamental role in the global nitrogen cycling [1]. Hitherto, four autotrophic AOP types are uncovered in nature. Among them, three aerobic AOP types, i.e., ammoniaoxidizing archaea $(A O A)$ of the Thaumarchaeota phylum, partial-nitrification ammonia-oxidizing bacteria (parAOB) of the Proteobacteria phylum, and comammox bacteria (comAOB) of the Nitrospirae phylum, can drive the oxidation of ammonia to nitrite during the nitrification step [2-4]. While the remaining one anaerobic AOP type, i.e., anaerobic AOB (AnAOB) of the Planctomycetes phylum, can functionates the oxidation of ammonia to nitrogen gas via the anammox procedure [5].

Sponges are widely distributed ecological participators in marine ecosystems [6]. Sponges often host abundant diverse microbiota [7-9] and excrete ammonia as a waste product which is toxic with its accumulation in sponge tissues [10]. The accumulated ammonia in sponges can be scavenged by AOP, since nitrification and anammox strategies have been confirmed in sponges [11-13].

The amoA gene, encoding a subunit of ammonia monooxygenase in $\mathrm{AOA}$ and parAOB, is commonly used as a phylogenetic marker to verify the residence of $A O A$ and parAOB in environments [14-16]. For example, amoA gene or transcript-based analyses have revealed diverse Thaumarchaeota AOA or Nitrosospira parAOB in sponges [17-19]. Besides, amoA gene and transcript co-detection surveys demonstrated that parAOB amoA genes could be detected in the sponges Antho dichotoma and Phakellia ventilabrum whereas their transcript counterparts were only revealed from $A$. dichotoma [20], suggesting that some sponge-associated AOP may be not metabolically active at the time of sampling [20]. 
Metagenomic and metatranscriptomic analyses have also disclosed abundant amo homologues of Thaumarchaeota AOA and Proteobacteria parAOB in different sponges [21-26]. Besides, metagenomeassembled genomes have further revealed various AOA species, e.g., Nitrosopumilus sp. LS_AOA, Ca. Nitrosospongia ianthellae, Ca. Nitrosopumilus hexadellus, Ca. Nitrosopumilus detritiferus, and Ca. Cenporiarchaeum stylissum in sponges [27-29]. These studies demonstrate the remarkable function of $\mathrm{AOA}$ or parAOB in aerobic ammonia oxidation in sponges.

The amo $A$ gene in comAOB, distinctive from its homologues in $\mathrm{AOA}$ and parAOB, is also a useful biomarker to screen the comAOB in ecosystems [30]. amoA gene-based studies have revealed diverse comAOB in marine environments, such as estuary sediments [31], mangrove sediments [32], and estuarine tidal flat wetlands [33]. As a comparison, comAOB has not been reported inhabiting sponges yet. Co-existence of Nitrosopumilus and Nitrospira was found in the sponges Theonella swinhoei [34] and Cymbastela concentrica [35]. However, whether these sponge-associated Nitrospira belonged to comAOB were not verified. Further comAOB amoA gene-based assessment [30] would be helpful to verify the inhabitancy of comAOB in sponges.

The $h z s A$ or $h z s B$ gene encoding a subunit of hydrazine synthase in $A n A O B$ is used as a phylomarker to uncover the AnAOB in niches [36]. An attempt to detect AnAOB $h z s A$ fragments from sponges was failed [19]. However, co-detection of $a m o A$ and AnAOB-specific 16SrRNA genes have verified the Nitrosarchaeum AOA and Scalindua AnAOB in the sponge Geodia barretti [13], and Nitrosospira AOB and Brocadia AnAOB in the sponges Ircinia strobilina and Mycale laxissima [20]. Therefore, the function of AnAOB in anaerobic ammonia oxidation should not be neglected in sponges.

Notably, the presence of the functional genes (e.g., amoA or $h z s B$ ) in ecosystems is not the direct evidence of AOP metabolic activity. Rather, the corresponding transcripts of genes are more suitable to represent the functional activity, and are more sensitive when facing environmental variables [37]. Thus, analysis of the ammonia-oxidation transcripts would provide valuable hints on the active ammoniaoxidizing microorganisms in environments [38], such as in sponges [20].

Since the ubiquity of comAOB in various environments [39], it is necessary to reappraise and expand the understanding of the AOP community in environments, such as sponges and the ambient niches. Cinachyrella australiensis (Demospongiae Class, Tetractinellida Order, Tetillidae Family) is an ecologically dominant and representative sponge species of the coastal community [40]. This sponge distributes in a broad range of Indo-Pacific [41]. A previous study has discovered both aerobic bacteria (e.g., Nitrospira and Methylococcales) and anaerobic bacteria (e.g., Anaerolineae and Chromatiales) in $C$. australiensis [42], implying the presence of oxic-anoxic microenvironments in this sponge. Here, $C$. australiensis was chosen to access the presence, diversity, and abundance of the active AOP community in sponge and the ambient environments. To this aim, transcripts of phylomarkers involved in aerobic and anaerobic ammonia oxidation procedures were analyzed to uncover and compare the active ammonia-oxidizers in $C$. australiensis, ambient seawater, and sediment niches. 


\section{Materials And Methods}

\section{Study Site and Sampling}

The sponge individuals were collected at the low tide sites S1 $\left(109^{\circ} 29^{\prime} 33^{\prime \prime} \mathrm{E} 18^{\circ} 15^{\prime} 37^{\prime \prime} \mathrm{N}\right), \mathrm{S} 2\left(109^{\circ} 29^{\prime} 11^{\prime \prime}\right.$ E $\left.18^{\circ} 15^{\prime} 37^{\prime \prime} N\right)$, and S3 $\left(109^{\circ} 26^{\prime} 18^{\prime \prime}\right.$ E $\left.18^{\circ} 15^{\prime} 37^{\prime \prime} N\right)$ from the intertidal zone of Hainan Island in the South China Sea at 8:00 $-10: 00$ am in July $6^{\text {th }}, 2019$. The seawater temperature was $27.2-27.4^{\circ} \mathrm{C}$. The sponge is solitary individual of globular size in appearance, typically up to $4-6 \mathrm{~cm}$ diameter. In each site, triplicate samples of sponge tissue slice, ambient seawater (two liters each), and ambient sediment $(0-2 \mathrm{~cm}, \sim 5 \mathrm{~g})$ were separately collected (Fig. S1 A and B). Collections and pretreatments of sponge, seawater, and sediment samples referred to the reported strategy $[19,20,43]$ before being transferred into the RNAprotect Bacteria Reagent (Qiagen, Hilden, Germany). Identification of the sponge species based on gross morphology and PCR confirmation of the mitochondrial coxl (cytochrome c oxidase subunit I) gene using the primer pair CinaF2/dgHCO2198 [44]. The amplified cox/ clone gene showed $99 \%$ nucleotide sequence identity to the reported $C$. australiensis voucher LB_815 mitochondrial cox 1 gene (JX177880) and was submitted to GenBank with the accession number MT913441. The time between sample acquisition and fixation was no longer than 20 min to minimize RNA degradation [45]. All the RNA protector-fixed samples were stored at $-80^{\circ} \mathrm{C}$ before total RNA and DNA extraction within two weeks.

\section{RNA, DNA Extraction and cDNA Synthesis}

RNA protector-fixed $C$. australiensis, seawater, and sediment samples were ground in liquid nitrogen with a sterilized mortar and pestle. Both RNA and DNA were extracted from ground powders using the PrepRNA/DNA Mini Kit (Qiagen, Hilden, Germany) following the manufacturer's instruction. RNA and DNA were separately extracted from each sample of $C$. australiensis, seawater, and sediment. RNase-free DNase I (Fermentas, Hanover, USA) was used to digest the residual genomic DNA at $37^{\circ} \mathrm{C}$ for $60 \mathrm{~min}$. RNA quality and integrity were checked by gel electrophoresis and by examining the A260/A280 ratio (ranging from 1.97 to 2.02) using a NanoDrop spectrophotometer (NanoDrop Technologies, Wilmington, USA). The final RNA concentration and purity were quantified using the Qubit system (Invitrogen, Darmstadt, Germany). First-strand cDNA synthesis was performed using the SuperScript FirstStrand Synthesis System (Invitrogen, Carlsbad, USA). Each reaction volume was10 $\mu$ l containing $100 \mathrm{ng}$ RNA, $0.5 \mu \mathrm{l}$ random hexamer primer $\left(50 \mathrm{ng} \mu^{-1}\right), 5 \mu \mathrm{cDNA}$ Synthesis Mix, and proper RNase-free water. This reaction system was incubated at $25^{\circ} \mathrm{C}$ for $10 \mathrm{~min}$ and then $50^{\circ} \mathrm{C}$ for $50 \mathrm{~min}$ and terminated at $85^{\circ} \mathrm{C}$ for $5 \mathrm{~min}$. All CDNA aliquots were stored at $-80^{\circ} \mathrm{C}$ before PCR amplification.

\section{Amplification and Sequencing}

The AOA amoA, AAOB amoA, COAOB amoA, and AnAOB hzsB gene fragments were amplified, respectively, using the CDNA and DNA templates with the primers listed in Table 1. PCR amplifications were performed in a total volume of $40 \mu \mathrm{l}$ containing $2 \mu \mathrm{l}$ cDNA or $2 \mathrm{ng}$ DNA, $0.1 \mu \mathrm{M}$ of each primer, and $20 \mu$ T TaqMasterMix (CoWin Biotech, Beijing, China) on a Thermocycler (Eppendorf, Hamburg, Germany) according to the following procedures: $95^{\circ} \mathrm{C}$ for 5 min; followed by 30 cycles at $95^{\circ} \mathrm{C}$ for $40 \mathrm{~s}$, annealing 
(temperature referring to Table 1) for $30 \mathrm{~s}$ and $72^{\circ} \mathrm{C}$ for $30 \mathrm{~s}$, and finally $72^{\circ} \mathrm{C}$ for $10 \mathrm{~min}$. For negative control, a similar procedure was carried out using purified RNA to ensure that there was no genomic DNA contamination. PCR products originated from the triplicate samples of $C$. australiensis, seawater, or sediment from each sampling site were pooled to reduce potential amplification bias and maximize the transcript richness referring to the previous strategies [19]. The presence and sizes of these amplification products were estimated by gel electrophoresis (1.5\% agarose gel). Since this study focused on the transcriptional activity of the ammonia-oxidizing community, the performance of DNA-based PCR amplification was to only test the presence of the targeted genes in the investigated biotopes, whose PCR products were not sequenced [19]. cDNA-based PCR products were gel-purified with MinElute Gel Extraction Kit (Qiagen), cloned with pUCm-T Vector Rapid Cloning Kit (Sangon Biotech, Shanghai), and transformed to the DH5a competent cells (Sangon Biotech) according to the standardized instructions. The positive clones were screened by ampicillin resistance and identified by PCR screening with vectorspecific M13 primers. A variable number of clones (13 - 69) from each clone library were sequenced (Table S1) on an ABI 3100 capillary sequencer (Sangon Corp., Shanghai, China).

\section{Sequence Analysis}

All the obtained nucleotide sequences were trimmed manually by using ClustalW implemented in MEGA Q with default settings [46]. The trimmed sequences were performed BLAST searches against the NCBI Nucleotide database. A phylotype was defined by $3 \%$ dissimilarity threshold $[47,48]$ for amoA, or by $5 \%$ for $h z s B$ [36], using the Mothur Version 1.44 .1 package [49]. Phylotype representative sequences were taxonomically classified using BLASTn against NCBI Nucleotide database. Rarefaction curves and Good's coverage estimators were determined using the Mothur package [49] to estimate whether the sequencing depth is enough to cover most of the transcribed genes in each clone library.

One representative sequence from each phylotype and its closest sequence retrieved from the NCBI Nucleotide database were aligned using ClustaIW implemented in the MEGA \& [46]. Maximum-likelihood $(\mathrm{ML})$ tree was constructed by using the MEGA $\otimes$ with the Kimura-2 parameter model according to a published guideline [50]. Bootstrap analysis was used to estimate the reliability of phylogenetic reconstructions (1000 replicates).

\section{RT-qPCR Assays}

RT-qPCR assays were performed using an ABI 7500 Fast Real-time qPCR platform (Applied Biosystems, Foster, USA), following the reported strategy on sponges [19]. Gene expression was tested using technical triplicates for each sample of $C$. australiensis, seawater, and sediment. PCR was performed in a total volume of $25 \mu \mathrm{l}$ containing $12.5 \mu \mathrm{l}$ of SYBR Premix Ex Taq ${ }^{\text {TM }}$ II (Takara, Dalian, China), $1 \mu \mathrm{l}$ of cDNA template (tenfold serial dilution), and $0.1 \mu \mathrm{M}$ of each primer (Table 1). PCR thermocycling steps were set

as follows: $95^{\circ} \mathrm{C}$ for $5 \mathrm{~min}$ and 40 cycles at $95^{\circ} \mathrm{C}$ for $45 \mathrm{~s}$, annealing (temperature setting showed in Table 1) for $45 \mathrm{~s}$, and $72^{\circ} \mathrm{C}$ for $45 \mathrm{~s}$. For quantification, standard curves (log-linear $\mathrm{R}^{2}>0.99, E=92 \%-110 \%$ ) were generated using purified and quantified plasmids containing AOA amoA (sequence of the clone 
AOA-spg-1, GenBank ID MT925791), parAOB amoA (sequence of the clone parAOB-spg-1, GenBank ID MT925730), comAOB amoA (sequence of the clone comAOB-sed-1, GenBank ID MT925742), or AnAOB $h z s B$ (sequence of the clone AnAOB-spg-1, GenBank ID MT925769) fragment in a dilution series that spanned from $10^{1}$ to $10^{7}$ gene copies per reaction. All standard dilutions were prepared in $10 \mathrm{ng} \mathrm{Hl}^{-1}$ aqueous tRNA solution (Sigma-Aldrich, Steinheim, Germany). Plasmid DNA was extracted using the PurePlasmid 96 Kit (CoWin Biotech), and the plasmid concentration was measured using the Qubit system (Invitrogen). Since the sequences of the vector and PCR insert are known, copy numbers of transcribed $a m o A$ or $h z s B$ genes were directly calculated according to the reported formula: copy numbers $\mu \mathrm{l}^{-1}=\left(\mathrm{A} \times 6.022 \times 10^{23}\right) \times(660 \times \mathrm{B})^{-1}$, where $\mathrm{A}$ is the plasmid concentration $\left(\mathrm{g} \mathrm{\mu l} \mathrm{l}^{-1}\right), \mathrm{B}$ is the recombinant plasmid length (bp) containing the $a m o A$ or $h z s B$ fragment, $6.022 \times 10^{23}$ is the Avogadro's number, and 660 is the average molecular weight of $1 \mathrm{bp} \mathrm{[51].} \mathrm{For} \mathrm{negative} \mathrm{control,} \mathrm{a} \mathrm{similar} \mathrm{procedure}$ was performed using purified RNA to ensure that there was no genomic DNA contamination. After the qPCR assay, the specificity of amplification was verified by the generation of melting curves (in steps of $0.5^{\circ} \mathrm{C}$ for $5 \mathrm{~s}$, with temperatures ranging from 60 to $95^{\circ} \mathrm{C}$ ) and the qPCR product size and specificity were checked by $2 \%$ agarose gel electrophoresis.

\section{Statistical Analysis}

Data acquisition of the qPCR assay was performed using the 7500 System SDS Software Version 1.2 (Applied Biosystems). One-way analysis of variance (ANOVA) was performed to evaluate the abundance variations of the amoA or $h z s B$ transcripts between $C$. australiensis, seawater, and sediment niches using the commands in SPSS 19.0. The thetaYC matrix distances based on the amoA or hzsB transcript sequences were calculated via Mothur commands and were visualized by the principal co-ordinate analysis (PCoA) in Canoco 5.0. Comparison between the amoA or $h z s B$-harboring communities from $C$. australiensis, seawater, and sediment niches were analyzed using the analysis of similarity statistics (ANOSIM) on thetaYC indices through Mothur. Statistical differences were determined at the level of $a=$ 0.05 .

\section{Results}

\section{Rarefaction Curves and Good's Coverage Values}

PCR and sequencing result showed that $A O A$ amo $A$ was detected from $C$. australiensis, seawater, and sediment niches; parAOB amoA and AnAOB $h z s B$ were revealed from $C$. australiensis and sediment niches, whereas comAOB amoA was only uncovered from sediment niches (Fig. S2). Rarefaction curve analysis showed that most of the $a m o A$ and $h z s B$ transcript curves reach an asymptote based on $3 \%$ or $5 \%$ nucleotide sequence dissimilarity (Fig. S3), consistent with the Good's Coverage values ranging from $76.9 \%-100 \%$ (Table S1). Therefore, enough $a m o A$ and $h z s B$ transcript clones were sequenced to represent their diversity in corresponding clone libraries. 
The phylotype sequences determined in this study were submitted to GenBank under accession numbers MT925778 - MT925797 (for the AOA amoA sequences), MT925728 - MT925741 (for the parAOB amoA sequences), MT925742 - MT925755 (for the comAOB amoA sequences), and MT925756-MT925777 (for the AnAOB $h z s B$ sequences).

\section{Community Compositions Of Active Aop}

Most of the AOA amoA transcripts were taxonomically classified into the Nitrosopumilus, Nitrosotenuis, Nitrososphaera, Nitrosopelagicus, and Cenarchaeum taxa, and the remaining ones ( $7.3 \%$ of total) cannot gather into a definite taxon (Unclassified). As shown in Fig. 1A, AOA population in $C$. australiensis was composed of Nitrosopumilus, Nitrosopelagicus, and Cenarchaeum. Such a composition differed from that in sediment niches (consisting of Nitrosopumilus, Cenarchaeum, and Unclassified) and in seawater niches (consisting of Nitrosopumilus, Nitrosotenuis, Nitrosopelagicus, Cenarchaeum, and Unclassified). Similarly, parAOB or AnAOB compositions were different between $C$. australiensis and sediment niches. Thus, the parAOB population consisted of Nitrosospira in C. australiensis and Nitrosospira and Nitrosomonas in sediment niches (Fig. 1B); while the AnAOB population comprised Kuenenia and Scalindua in C. australiensis and Brocadia, Scalindua, and Jettenia in sediment niches (Fig. 1D). Moreover, Nitrospira Clade A and Clade B composed the comAOB population in sediment niches with Clade $A$ taking a dominant proportion (95.6\% of total) (Fig. 1C).

\section{Community Dissimilarity Of Aop Communities Between Different Niches}

PCoA based on the thetaYC matrix distance showed that AOA populations within $C$. australiensis, seawater, and sediment niches were clearly separated by axes PC1 (explaining $71.2 \%$ of the variation) and PC2 (explaining $18.3 \%$ of the variation) (Fig. 2A). Similarly, the parAOB or AnAOB populations from $C$. australiensis and sediment niches were clearly separated by axes PC1 (explaining $52.6 \%$ or $68.5 \%$ of the variation) and PC2 (explaining $16.8 \%$ or $20.4 \%$ of the variation) (Fig. 2B and C). ANOSIM results based on thetaYC indices showed that the $A O A$, parAOB, or $A \cap A O B$ populations within $C$. australiensis, seawater, and sediment niches was significantly different from each other $(r=0.812-0.639, p=0.002-0.028<$ 0.05).

\section{Phylogeny of amoA and hzsB Transcript Phylotypes}

All the AOA amoA transcript phylotypes were most similar to the uncultured environmental sequences from sponges, seawaters, and sediments (Table S3) and phylogenetically fell into six clusters (Fig. 3). Basically, five phylotypes fell into the Nitrosopumilus cluster; these five phylotypes related to Nitrosopumilus spp. and the uncultured sequences from aquarium biofilter, marine sediments, and seawaters. One phylotype gathered into the Nitrosotenuis cluster and was similar to Ca. Nitrosotenuis spp. and the uncultured sequences from the Black Sea. Another phylotype falling into the Nitrososphaera 
cluster was related to Ca. Nitrososphaera spp. and the uncultured sequence from marine sediment. Four phylotypes gathered into the Nitrosopelagicus cluster; these phylotypes were closely related to $\mathrm{Ca}$. Nitrosopelagicus brevis, Crenarchaeote SCGC AAA288-J14, and the uncultured sequences from seawater and sponge. Another four phylotypes were ascribed into the Cenarchaeum cluster which were closely related to Cenarchaeum symbiosum and the uncultured sequences from seawater and sponge. Besides, the remaining four phylotypes gathered into the Unclassified cluster; these phylotypes were similar to the uncultured sequences from marine sediments and seawaters. Thus, a complex active AOA population was uncovered from $C$. australiensis, seawater, and sediment niches. Analysis of the Proportion of AOA amoA phylotypes in each niche showed that, The phylotypes accounting for the highest proportion in turn fell into the Cenarchaeum, Nitrosopumilus, and Nitrosopelagicus cluster in C. australiensis, sediment, and seawater niches, respectively.

The parAOB amoA transcript phylotypes which were most similar to the uncultured environmental sequences (Table S3) fell into the Nitrosospira and Nitrosomonas clusters (Fig. 4A). Eleven phylotypes fell into the Nitrosospira cluster and were mainly related to Nitrosospira spp. and the uncultured sequences from various sponges and marine sediments; while the remaining three sediment-derived phylotypes gathered into the Nitrosomonas cluster and were related to Nitrosomonas spp. and the uncultured sequences from marine sediments and nitrifying granules (Fig. 4A). The phylotype accounting for the highest proportion in turn gathered into the Nitrosospira and Nitrosomonas cluster in $C$. australiensis and sediment niches, respectively.

Specially, comAOB amoA transcripts were most similar to the uncultured environmental sequences from marine sediments and other niches (Table S3) and gathered into the Nitrospira Clade A and B clusters (Fig. 4B), according to their distinct divergence [4]. Clade A included 12 phylotypes which were closely related to the sequences from various types of sediments, wastewater treatment plant, biofilter sand, and the known comAOB species, i.e., Ca. Nitrospira nitrificans, Ca. Nitrospira nitrosa, Ca. Nitrospira inopinata, and Nitrospira moscoviensis. The Clade B containing two phylotypes were similar to the wetland derived sequences and the Ca. Nitrospira sp. comreactor17. Thus, a complex comAOB population with transcriptional activity inhabits the surface sediment adjacent to the sponge $C$. australiensis. The phylotype accounting for the highest proportion gathered into the Nitrospira Clade A cluster in sediment niches.

All the AnAOB $h z s B$ transcript phylotypes were most similar to the uncultured environmental sequences from the South China Sea and other soil or sediment environments (Table S3) and fell into four clusters (Fig. 5). Briefly, the Brocadia cluster including seven phylotypes were related to the sequences from granular sludge and different types of wetlands. The Jettenia cluster included one phylotype related to the sequence from paddy soil. Two phylotype fell into the Kuenenia cluster and were similar to the sequence from South China Sea sediment, wastewater treatment plant, and Ca. Kuenenia stuttgartiensis; while the Scalindua cluster included 12 phylotypes which were closely related to Ca. Scalindua rubra and the South China Sea sediment-derived sequences. The phylotypes accounting for the highest proportion in turn gathered into the Scalindua and Brocadia cluster in C. australiensis and sediment niches, 
respectively. Taken together, the $a m o A$ and $h z s B$ transcript phylotypes fell into different clusters and were clustered with the uncultured environmental sequences from marine sponges, seawaters, sediments, and other aquatic niches.

\section{Quantification of amoA and hzsB Transcripts}

Quantitative surveys showed that (Fig. 6 and Table S3), transcript abundances of AOA amoA > parAOB amoA $>$ AnAOB $h z s B$ in $C$. australiensis niches $(r=0.894-0.625, \mathrm{p}=0.001-0.035)$ while, transcript abundances of $A O A$ amoA $>$ parAOB $a m o A>c o m A O B$ amoA and AnAOB $h z s B n$ sediment niches $(r=$ $0.792-0.584, \mathrm{p}=0.008-0.042)$. In seawater, copy of $A O A$ amo $A$ transcripts was $(8.73 \pm 0.22) \times 10^{7}$ copies $\mathrm{ng}^{-1}$ seawater RNA, whereas other AOP type were below the limit of PCR detection. Thus, transcript abundance of $\mathrm{AOA}$ amoA, ParAOB amoA, ComAOB amoA, and AnAOB hzsB varied in $C$. australiensis, ambient seawater, or sediment niches.

\section{Discussion}

An active AOP community composing of $A O A$, parAOB, and $A n A O B$ was revealed in the sponge $C$. australiensis. Such a AOP community was significantly different from that in ambient seawater (consisting of $A O A$ ) and sediment niches (consisting of $A O A$, parAOB, comAOB, and AnAOB). Such a finding was consistent with previous studies that microorganism compositions were significantly varied between sponges, environmental seawaters, and sediments $[43,52]$. Therefore, marine sponges may have eco-physiological preferences for specific microbes distinctive from ambient seawater and sediment niches [53].

AOA are ubiquitous and significant contributors to nitrogen cycling in marine environments [54]. Nitrosopumilus, Nitrosopelagicus, Nitrosotenuis, Nitrososphaera, and Cenarchaeum AOA were detected (Fig. 1). The active AOA population in C. australiensis mainly consisting of Nitrosopumilus, Nitrosopelagicus, and Cenarchaeum differed from that in sediment niches (consisting of Nitrosopumilus, Cenarchaeum) and in seawater niches (consisting of Nitrosopumilus, Nitrosotenuis, Nitrosopelagicus, Cenarchaeum) (Figs. 1A and 2A). Generally, there is an obvious niche differentiation of AOA population between $C$. australiensis, and their ambient seawater and sediment niches. Similar condition has been found in another case that the South China Sea sponges harbored an AOA population (Nitrosopelagicus and Cenarchaeum) differed from that in ambient seawaters (Nitrosopumilus) [19]. Among the detected AOA lineages, Nitrosopumilus was detected from $C$. australiensis, seawater, and sediment niches (Fig. 1A), in agreement with previous findings that Nitrosopumilus is prevalent in ammonia oxidation in marine sponges (Fig. S4), seawaters, and sediments [19, 55, 56]. Nitrosopelagicus and Cenarchaeum were detected from $C$. australiensis and seawater niches (Fig. 1A), consonant with former reports that these two AOA lineages are commonly found in various sponges (Fig. S4) and seawaters [24, 57]. Nitrosotenuis and Nitrososphaera were detected from seawater and sediment niches, respectively (Fig. 1A), consistent with previous revelations that Nitrosotenuis can be found widely distributed in seawaters [58] while Nitrososphaera represents an AOA genus frequently found in marine sediments [59]. 
Generally, there is an obvious niche differentiation of putative active AOA population among $C$. australiensis, ambient seawater, and sediment niches.

The parAOB also contribute to ammonia oxidation in marine environments [60]. The parAOB population in $C$. australiensis comprised of Nitrosospira distinctive from that in sediment niches consisting of Nitrosospira and Nitrosomonas (Figs. 1B and 2B). Conclusion of the reported sponge-associated parAOB amoA sequences showed that, Nitrosospira amoA sequences were reported in diverse sponges (Fig. S5), while Nitrosomonas amoA homologues were only uncovered from few sponges, e.g., Neamphius huxleyi and Placospongia sp. (Fig. S5), indicating that Nitrosospira rather than Nitrosomonas may the dominate the parAOB population in sponges. Many studies also demonstrated that Nitrosomonas and Nitrosospira parAOB have also been uncovered from marine sediments [61-63], in agreement with our finding (Fig. 1). Whereas the negative detection of parAOB in seawaters different from previous findings that parAOB residence in seawaters $[17,64,65]$. Therefore, the presence of parAOB in marine environments may be varied in different geographic areas and a specific niche, e.g., sponge, seawater, or sediment niche may harbor a specific parAOB population.

A comAOB population composed of Nitrospira Clade A and B lineages (Fig. 3) was detected in sediments (Fig. $1 \mathrm{C}$ and Fig. S2). Such a comAOB amoA population composition were also found in marine coastal waters and sediments $[31-33,66,67]$ and river waters and sediments [68]. Such a comAOB population differs from that in eutrophic lake sediments [69] and river tidal flat sediments [31] where only Nitrospira clade $A$ were detected. The comAOB amoA was undetectable in seawaters, in agreement with the findings in former studies [4, 70]. Besides, no comAOB amoA fragment was detected from $C$. australiensis, and no reports have confirmed the presence of comAOB in sponges so far. Therefore, whether the comAOB resident in sponges needs further investigation. These findings indicate the niche differentiation of comAOB in different environments.

AnAOB greatly contributes to marine nitrogen removal from the oceans [71]. The AnAOB population in $C$. australiensis niches comprised of Kuenenia and Scalindua (Fig. 1) which was different from the Brocadia AnAOB population in the sponge Mycale laxissima [20]. Moreover, AnAOB population in sediment niches were divergent from that in C. australiensis niches (Fig. 2C) and consisted of Brocadia, Jettenia, Kuenenia, and Scalindua (Fig. 1D), consistent with that in China's coastal wetlands [72], but different from that in surface sediments of the Bohai Sea [73] and north marginal seas of China [74] which was composed of Scalindua, Jettenia, and Anammoxoglobus. Conclusively, the ecological niche segregation of AnAOB was prevalent in marine environments, such as in sponges, seawaters, and sediments.

Quantitative surveys of $a m o A$ or $h z s B$ transcripts demonstrated that $A O A$ amoA transcripts were either exclusively detectable or were higher in abundance than parAOB amoA, comAOB amoA and AnAOB hzsB transcripts by orders of magnitude in $C$. australiensis, seawater, and sediment niches (Fig. 6). Such a finding indicated the dominant transcriptional expression of $A O A$ in these niches. Similar condition has been revealed from the cold-water sponges where higher amoA transcripts abundance of AOA than that of parAOB were detected [12]. Based on the nitrification kinetics of pure cultures, ammonia affinity of 
ammonia-oxidizing species ranking from high to low is marine $A O A$, comAOB, terrestrial $A O A$, and parAOB [75]. A higher ammonia affinity of $A O A$ would contribute to their survival in the oligotrophic ocean. Meanwhile, although comAOB showed a higher ammonia affinity than parAOB, both parAOB and comAOB were uncovered in sediment niches, while parAOB rather than comAOB were uncovered in $C$. australiensis. Therefore, besides ammonia contents, other environmental factors may also influence the residence of comAOB in sponges, which need further investigation.

Generally, microbially mediated ammonia oxidation process by phylogenetically divergent AOP lineages in the sponge $C$. australiensis, ambient seawater, and sediment niches. Certainly, some aspects need further study. For example, the comAOB amoA sequence was not detected from $C$. australiensis.

Therefore, more sponge species from distant geographic scales over different sampling timepoints can be investigated to verify the residence of comAOB in sponges. Additionally, the investigated $C$. australiensis, ambient seawater, and sediment niches were only collected at one timepoint rather than serial timepoints. Temporal change in gene expression is possible, such as the AOA and parAOB amoA transcripts in coastal sediments [76]. Therefore, more data from different sponges in time series will give us a better insight into the ammonia oxidation and other nitrogen metabolic processes.

\section{Conclusion}

In this study, the community structure and abundance of active ammonia-oxidizing microbiota in the sponge $C$. australiensis, ambient seawaters, and sediments were investigated using transcript-based strategies. Active AOP community selectively consisting of $A O A$, parAOB, comAOB, or $A \cap A O B$ was uncovered inhabiting $C$. australiensis, seawater, and sediment niches. The AOP community in $C$. australiensis was significantly different from that in ambient seawater and sediment niches. AOA amoA transcripts were exclusive or higher in abundance than parAOB amoA, comAOB amoA, or AnAOB $h z s B$ transcripts by orders of magnitude in each niche type. This study indicates the obvious divergence of AOP population structures and significant variations of AOP transcriptional expressions among $C$. australiensis, ambient seawater, and sediment niches. This research would extend our understanding of the putative metabolic activity and ecological functions of the ammonia-oxidizing microbiota within marine sponges and the ambient environments.

\section{Declarations}

\section{Author contribution}

Study conception and design: FG, SL, LZ, and HT; acquisition of data: FG, SL, LZ, and HT; bioinformatic analysis: FG and SL; analysis and interpretation of data: FG; drafting of manuscript: FG, SL, LZ, and HT; critical revision: FG, SL, LZ, and HT.

Conflict of interest The authors declare no competing interests. 


\section{References}

1. Lehtovirta-Morley LE (2018) Ammonia oxidation: Ecology, physiology, biochemistry and why they must all come together. FEMS Microbiol Lett 365:fny058. doi:10.1093/femsle/fny058

2. Pester M, Schleper C, Wagner M (2011) The Thaumarchaeota: an emerging view of their phylogeny and ecophysiology. Curr Opin Microbiol 14:300-306. doi:10.1016/j.mib.2011.04.007

3. Kowalchuk GA, Stephen JR (2001) Ammonia-oxidizing bacteria: a model for molecular microbial ecology. Annu Rev Microbiol 55:485-529. doi:10.1146/annurev.micro.55.1.485

4. Daims H, Lebedeva EV, Pjevac P, Han P, Herbold C, Albertsen M, Jehmlich N, Palatinszky M, Vierheilig J, Bulaev A, Kirkegaard RH, von Bergen M, Rattei T, Bendinger B, Nielsen PH, Wagner M (2015) Complete nitrification by Nitrospira bacteria. Nature 528:504-509. doi:10.1038/nature16461

5. Oshiki M, Satoh H, Okabe S (2016) Ecology and physiology of anaerobic ammonium oxidizing bacteria. Environ Microbiol 18:2784-2796. doi:10.1111/1462-2920.13134

6. Becerro MA (2008) Quantitative trends in sponge ecology research. Microb Ecol 29:167-177. doi:10.1111/j.1439-0485.2008.00234.x

7. Moitinho-Silva L, Nielsen S, Amir A, Gonzalez A, Ackermann GL, Cerrano C, Astudillo-Garcia C, Easson C, Sipkema D, Liu F, Steinert G, Kotoulas G, McCormack GP, Feng G, Bell JJ, Vicente J, Björk JR, Montoya JM, Olson JB, Reveillaud J, Steindler L, Pineda M-C, Marra MV, Ilan M, Taylor MW, Polymenakou P, Erwin PM, Schupp PJ, Simister RL, Knight R, Thacker RW, Costa R, Hill RT, LopezLegentil S, Dailianis T, Ravasi T, Hentschel U, Li Z, Webster NS, Thomas T (2017) The sponge microbiome project. GigaScience 6:1-7. doi:10.1093/gigascience/gix077

8. Cleary DFR, Polónia ARM, Huang YM, Putchakarn S, Gomes NCM, de Voogd NJ (2019) A comparison of prokaryote communities inhabiting sponges, bacterial mats, sediment and seawater in Southeast Asian coral reefs. FEMS Microbiol Ecol 95:fiz169. doi:10.1093/femsec/fiz169

9. Steinert G, Busch K, Bayer K, Kodami S, Arbizu PM, Kelly M, Mills S, Erpenbeck D, Dohrmann M, Wörheide G, Hentschel U, Schupp PJ (2020) Compositional and quantitative insights into bacterial and archaeal communities of South Pacific deep-sea sponges (Demospongiae and Hexactinellida). Front Microbiol 11:716. doi:10.3389/fmicb.2020.00716

10. Hentschel U, Piel J, Degnan SM, Taylor MW (2012) Genomic insights into the marine sponge microbiome. Nat Rev Microbiol 10:641-654. doi:10.1038/nrmicro2839

11. Subina NS, Thorat BR, Gonsalves MJ (2018) Nitrification in intertidal sponge Cinachyrella cavernosa. Aquat Ecol 52:155-164. doi:10.1007/s10452-018-9651-x

12. Radax R, Hoffmann F, Rapp HT, Leininger S, Schleper C (2012) Ammonia-oxidizing archaea as main drivers of nitrification in cold-water sponges. Environ Microbiol 14:909-923. doi:10.1111/j.14622920.2011.02661.x

13. Hoffmann F, Radax R, Woebken D, Holtappels M, Lavik G, Rapp HT, Schläppy ML, Schleper C, Kuypers MM (2009) Complex nitrogen cycling in the sponge Geodia barretti. Environ Microbiol 11:22282243. doi:10.1111/j.1462-2920.2009.01944.x 
14. Pester M, Rattei T, Flechl S, Gröngröft A, Richter A, Overmann J, Reinhold-Hurek B, Loy A, Wagner M (2012) amoA-based consensus phylogeny of ammonia-oxidizing archaea and deep sequencing of amoA genes from soils of four different geographic regions. Environ Microbiol 14:525-539. doi:10.1111/j.1462-2920.2011.02666.x

15. Rotthauwe JH, Witzel KP, Liesack W (1997) The ammonia monooxygenase structural gene amoA as a functional marker: molecular fine-scale analysis of natural ammonia-oxidizing populations. Appl Environ Microbiol 63:4704-4712. doi:10.1128/AEM.63.12.4704-4712.1997

16. Treusch AH, Leininger S, Kletzin A, Schuster SC, Klenk H-P, Schleper C (2005) Novel genes for nitrite reductase and Amo-related proteins indicate a role of uncultivated mesophilic crenarchaeota in nitrogen cycling. Environ Microbiol 7:1985-1995. doi:10.1111/j.1462-2920.2005.00906.x

17. Bayer K, Schmitt S, Hentschel U (2008) Physiology, phylogeny and in situ evidence for bacterial and archaeal nitrifiers in the marine sponge Aplysina aerophoba. Environ Microbiol 10:2942-2955. doi:10.1111/j.1462-2920.2008.01582.x

18. Han M, Liu F, Zhang F, Li Z, Lin H (2012) Bacterial and archaeal symbionts in the South China Sea sponge Phakellia fusca: community structure, relative abundance, and ammonia-oxidizing populations. Mar Biotechnol (NY) 14:701-713. doi:10.1007/s10126-012-9436-5

19. Feng G, Sun W, Zhang F, Orlić S, Li Z (2018) Functional transcripts indicate phylogenetically diverse active ammonia-scavenging microbiota in sympatric sponges. Mar Biotechnol (NY) 20:131-143. doi:10.1007/s10126-018-9797-5

20. Mohamed NM, Saito K, Tal Y, Hill RT (2010) Diversity of aerobic and anaerobic ammonia-oxidizing bacteria in marine sponges. ISME J 4:38-48. doi:10.1038/ismej.2009.84

21. Rua CP, Gregoracci GB, Santos EO, Soares AC, Francini-Filho RB, Thompson F (2015) Potential metabolic strategies of widely distributed holobionts in the oceanic archipelago of St Peter and St Paul (Brazil). FEMS Microbiol Ecol 91. doi: 10.1093/femsec/fiv043

22. Li Z, Wang Y, Li J, Liu F, He L, He Y, Wang S (2016) Metagenomic analysis of genes encoding nutrient cycling pathways in the microbiota of deep-sea and shallow-water sponges. Mar Biotechnol 18:659671. doi:10.1007/s10126-016-9725-5

23. Li Z, Wang Y, He L, Zheng H (2014) Metabolic profiles of prokaryotic and eukaryotic communities in deep-sea sponge Neamphius huxleyi indicated by metagenomics. Sci Rep 4:3895. doi:10.1038/srep03895

24. Fiore CL, Labrie M, Jarett JK, Lesser MP (2015) Transcriptional activity of the giant barrel sponge, Xestospongia muta Holobiont: molecular evidence for metabolic interchange. Front Microbiol 6:364. doi:10.3389/fmicb.2015.00364

25. Moitinho-Silva L, Seridi L, Ryu T, Voolstra CR, Ravasi T, Hentschel U (2014) Revealing microbial functional activities in the Red Sea sponge Stylissa carteri by metatranscriptomics. Environ Microbiol 16:3683-3698. doi:10.1111/1462-2920.12533

26. Radax R, Rattei T, Lanzen A, Bayer C, Rapp HT, Urich T, Schleper C (2012) Metatranscriptomics of the marine sponge Geodia barretti: tackling phylogeny and function of its microbial community. Environ 
Microbiol 14:1308-1324. doi:10.1111/j.1462-2920.2012.02714.x

27. Tian RM, Sun J, Cai L, Zhang WP, Zhou GW, Qiu JW, Qian PY (2016) The deep-sea glass sponge Lophophysema eversa harbors potential symbionts responsible for the nutrient conversions of carbon, nitrogen and sulfur. Environ Microbiol 18:2481-2494. doi:10.1111/1462-2920.13161

28. Zhang S, Song W, Wemheuer B, Reveillaud J, Webster N, Thomas T (2019) Comparative genomics reveals ecological and evolutionary insights into sponge-associated Thaumarchaeota. mSystems 4:e00288-e00219. doi:10.1128/mSystems.00288-19

29. Moeller FU, Webster NS, Herbold CW, Behnam F, Domman D, Albertsen M, Mooshammer M, Markert S, Turaev D, Becher D, Rattei T, Schweder T, Richter A, Watzka M, Nielsen PH, Wagner M (2019) Characterization of a thaumarchaeal symbiont that drives incomplete nitrification in the tropical sponge lanthella basta. Environ Microbiol 21:3831-3854. doi:10.1111/1462-2920.14732

30. Zhao Z, Huang G, He S, Zhou N, Wang M, Dang C, Wang J, Zheng M (2019) Abundance and community composition of comammox bacteria in different ecosystems by a universal primer set. Sci Total Environ 691:146-155. doi:10.1016/j.scitotenv.2019.07.131

31. Jiang Q, Xia F, Zhu T, Wang D, Quan Z (2019) Distribution of comammox and canonical ammoniaoxidizing bacteria in tidal flat sediments of the Yangtze River estuary at different depths over four seasons. J Appl Microbiol 127:533-543. doi:10.1111/jam.14337

32. Liu Z, Zhang C, Wei Q, Zhang S, Quan Z, Li M (2020) Temperature and salinity drive comammox community composition in mangrove ecosystems across southeastern China. Sci Total Environ 742:140456. doi:10.1016/j.scitotenv.2020.140456

33. Sun D, Tang X, Zhao M, Zhang Z, Hou L, Liu M, Wang B, Klümper U, Han P (2020) Distribution and diversity of comammox Nitrospira in coastal wetlands of China. Front Microbiol 11:589268. doi:10.3389/fmicb.2020.589268

34. Feng G, Sun W, Zhang F, Karthik L, Li Z (2016) Inhabitancy of active Nitrosopumilus-like ammoniaoxidizing archaea and Nitrospira nitrite-oxidizing bacteria in the sponge Theonella swinhoei. Sci Rep 6:24966. doi:10.1038/srep24966

35. Moitinho-Silva L, Díez-Vives C, Batani G, Esteves Al, Jahn MT, Thomas T (2017) Integrated metabolism in sponge-microbe symbiosis revealed by genome-centered metatranscriptomics. ISME J 11:1651-1666. doi:10.1038/ismej.2017.25

36. Zhou Z, Chen J, Meng H, Dvornyk V, Gu JD (2017) New PCR primers targeting hydrazine synthase and cytochrome $\mathrm{c}$ biogenesis proteins in anammox bacteria. Appl Microbiol Biotechnol 101:12671287. doi:10.1007/s00253-016-8013-7

37. Prosser JI, Nicol GW (2008) Relative contributions of archaea and bacteria to aerobic ammonia oxidation in the environment. Environ Microbiol 10:2931-2941. doi:10.1111/j.14622920.2008.01775.x

38. Klindworth A (2014) Diversity and activity of marine bacterioplankton during a diatom bloom in the North Sea assessed by total RNA and pyrotag sequencing. Mar Genomics 18:185-192. doi:10.1016/j.margen.2014.08.007 
39. Xia F, Wang JG, Zhu T, Zou B, Rhee SK, Quan ZX (2018) Ubiquity and diversity of complete ammonia oxidizers (Comammox). Appl Environ Microbiol 84. doi:10.1128/aem.01390-18

40. Mcdonald JI, Hooper JNA, Mcguinness KA (2002) Environmentally influenced variability in the morphology of Cinachyrella australiensis (Carter 1886) (Porifera: Spirophorida: Tetillidae). Mar Freshw Res 53:79-84. doi:10.1071/MF00153

41. Santodomingo N, Becking LE (2018) Unravelling the moons: review of the genera Paratetilla and Cinachyrella in the Indo-Pacific (Demospongiae, Tetractinellida, Tetillidae). Zookeys: 1-46. doi: 10.3897/zookeys.791.27546

42. Cleary DFR, Becking LE, Voogd NJd, Pires ACC, Polónia ARM, Egas C, Gomes NCM (2013) Habitatand host-related variation in sponge bacterial symbiont communities in Indonesian waters. FEMS Microbiol Ecol 85:465-482. doi:10.1111/1574-6941.12135

43. de Voogd NJ, Cleary DF, Polónia AR, Gomes NC (2015) Bacterial community composition and predicted functional ecology of sponges, sediment and seawater from the thousand islands reef complex, West Java, Indonesia. FEMS Microbiol Ecol 91:fiv019. doi:10.1093/femsec/fiv019

44. Szitenberg A, Becking LE, Vargas S, Fernandez JC, Santodomingo N, Wörheide G, Ilan M, Kelly M, Huchon D (2013) Phylogeny of Tetillidae (Porifera, Demospongiae, Spirophorida) based on three molecular markers. Mol Phylogenet Evol 67:509-519. doi:10.1016/j.ympev.2013.02.018

45. Öztürk B, de Jaeger L, Smidt H, Sipkema D (2013) Culture-dependent and independent approaches for identifying novel halogenases encoded by Crambe crambe (marine sponge) microbiota. Sci Rep 3:2780. doi:10.1038/srep02780

46. Kumar S, Stecher G, Li M, Knyaz C, Tamura K (2018) MEGA X: Molecular evolutionary genetics analysis across computing platforms. Mol Biol Evol 35:1547-1549. doi:10.1093/molbev/msy096

47. Wang B, Zhao J, Guo Z, Ma J, Xu H, Jia Z (2015) Differential contributions of ammonia oxidizers and nitrite oxidizers to nitrification in four paddy soils. ISME J 9:1062-1075. doi:10.1038/ismej.2014.194

48. Xu S, Wang B, Li Y, Jiang D, Zhou Y, Ding A, Zong Y, Ling X, Zhang S, Lu H (2020) Ubiquity, diversity, and activity of comammox Nitrospira in agricultural soils. Sci Total Environ 706:135684. doi:10.1016/j.scitotenv.2019.135684

49. Schloss PD, Westcott SL, Ryabin T, Hall JR, Hartmann M, Hollister EB, Lesniewski RA, Oakley BB, Parks DH, Robinson CJ, Sahl JW, Stres B, Thallinger GG, Van Horn DJ, Weber CF (2009) Introducing mothur: open-source, platform-independent, community-supported software for describing and comparing microbial communities. Appl Environ Microbiol 75:7537-7541. doi:10.1128/aem.0154109

50. Hall BG (2013) Building phylogenetic trees from molecular data with MEGA. Mol Biol Evol 30:12291235. doi:10.1093/molbev/mst012

51. Perini F, Casabianca A, Battocchi C, Accoroni S, Totti C, Penna A (2011) New approach using the realtime PCR method for estimation of the toxic marine dinoflagellate Ostreopsis cf. ovata in marine environment. PLoS One 6:e17699. doi:10.1371/journal.pone.0017699 
52. Polónia AR, Cleary DF, Freitas R, de Voogd NJ, Gomes NC (2015) The putative functional ecology and distribution of archaeal communities in sponges, sediment and seawater in a coral reef environment. Mol Ecol 24:409-423. doi:10.1111/mec.13024

53. Simister RL, Deines P, Botté ES, Webster NS, Taylor MW (2012) Sponge-specific clusters revisited: a comprehensive phylogeny of sponge-associated microorganisms. Environ Microbiol 14:517-524. doi:10.1111/j.1462-2920.2011.02664.x

54. Walker CB, de la Torre JR, Klotz MG, Urakawa H, Pinel N, Arp DJ, Brochier-Armanet C, Chain PS, Chan PP, Gollabgir A, Hemp J, Hügler M, Karr EA, Könneke M, Shin M, Lawton TJ, Lowe T, Martens-Habbena W, Sayavedra-Soto LA, Lang D, Sievert SM, Rosenzweig AC, Manning G, Stahl DA (2010) Nitrosopumilus maritimus genome reveals unique mechanisms for nitrification and autotrophy in globally distributed marine crenarchaea. Proc Natl Acad Sci U S A 107:8818-8823. doi:10.1073/pnas.0913533107

55. Hu J, Liu S, Yang W, He Z, Wang J, Liu H, Zheng P, Xi C, Ma F, Hu B (2019) Ecological success of the Nitrosopumilus and Nitrosospira clusters in the intertidal zone. Microb Ecol 78:555-564. doi:10.1007/s00248-019-01359-x

56. Zhang F, Pita L, Erwin PM, Abaid S, López-Legentil S, Hill RT (2014) Symbiotic archaea in marine sponges show stability and host specificity in community structure and ammonia oxidation functionality. FEMS Microbiol Ecol 90:699-707. doi:10.1111/1574-6941.12427

57. Santoro AE, Casciotti KL, Francis CA (2010) Activity, abundance and diversity of nitrifying archaea and bacteria in the central California Current. Environ Microbiol 12:1989-2006. doi:10.1111/j.14622920.2010.02205.x

58. Wong SK, ljichi M, Kaneko R, Kogure K, Hamasaki K (2018) Ammonia oxidizers in the sea-surface microlayer of a coastal marine inlet. PLoS One 13:e0202636. doi:10.1371/journal.pone.0202636

59. Yu S, Yao P, Liu J, Zhao B, Zhang G, Zhao M, Yu Z, Zhang XH (2016) Diversity, Abundance, and niche differentiation of ammonia-oxidizing prokaryotes in mud deposits of the Eastern China marginal seas. Front Microbiol 7:137. doi:10.3389/fmicb.2016.00137

60. He H, Zhen Y, Mi T, Fu L, Yu Z (2018) Ammonia-oxidizing archaea and bacteria differentially contribute to ammonia oxidation in sediments from adjacent waters of Rushan Bay, China. Front Microbiol 9. doi:10.3389/fmicb.2018.00116

61. Meyer B, Kuever J (2008) Phylogenetic diversity and spatial distribution of the microbial community associated with the Caribbean deep-water sponge Polymastia cf. corticata by $16 \mathrm{~S}$ rRNA, aprA, and amoA gene analysis. Microb Ecol 56:306-321. doi:10.1007/s00248-007-9348-5

62. Lagostina L, Goldhammer T, Røy H, Evans TW, Lever MA, Jørgensen BB, Petersen DG, Schramm A, Schreiber L (2015) Ammonia-oxidizing bacteria of the Nitrosospira cluster 1 dominate over ammonia-oxidizing archaea in oligotrophic surface sediments near the South Atlantic Gyre. Environ Microbiol Rep 7:404-413. doi:10.1111/1758-2229.12264

63. Vetterli A, Hietanen S, Leskinen E (2016) Spatial and temporal dynamics of ammonia oxidizers in the sediments of the Gulf of Finland, Baltic Sea. Mar Environ Res 113:153-163. 
doi:10.1016/j.marenvres.2015.12.008

64. Lam P, Lavik G, Jensen MM (2009) Revising the nitrogen cycle in the Peruvian oxygen minimum zone. Proc Natl Acad Sci U S A 106:4752-4757. doi:10.1073/pnas.0812444106

65. Valdés V, Fernandez C, Molina V, Escribano R (2018) Nitrogen excretion by copepods and its effect on ammonia-oxidizing communities from a coastal upwelling zone. Limnol Oceanogr 63:278-294. doi:10.1002/Ino.10629

66. Xia F, Wang JG, Zhu T, Zou B, Rhee SK, Quan ZX (2018) Ubiquity and diversity of complete ammonia oxidizers (Comammox). Appl Environ Microbiol 84:e01390-e01318. doi:10.1128/aem.01390-18

67. Yu C, Hou L, Zheng Y, Liu M, Yin G, Gao J, Liu C, Chang Y, Han P (2018) Evidence for complete nitrification in enrichment culture of tidal sediments and diversity analysis of clade a comammox Nitrospira in natural environments. Appl Microbiol Biotechnol 102:9363-9377. doi:10.1007/s00253018-9274-0

68. Liu S, Wang H, Chen L, Wang J, Zheng M, Liu S, Chen Q, Ni J (2020) Comammox Nitrospira within the Yangtze River continuum: community, biogeography, and ecological drivers. ISME J 14:2488-2504. doi:10.1038/s41396-020-0701-8

69. Xu Y, Liu G, Hua Y, Wan X, Hu J, Zhu D, Zhao J (2020) The diversity of comammox bacteria and the effect of sewage discharge on their abundance in eutrophic lake sediments. J Soils Sediments 20:2495-2503. doi:10.1007/s11368-020-02618-y

70. Xia F, Wang J-G, Zhu T, Zou B, Rhee S-K, Quan Z-X (2018) Ubiquity and diversity of complete ammonia oxidizers (Comammox). Appl Environ Microbiol 84:e01390-e01318.

doi:10.1128/aem.01390-18

71. Dalsgaard T, Thamdrup B, Canfield DE (2005) Anaerobic ammonium oxidation (anammox) in the marine environment. Res Microbiol 156:457-464. doi:10.1016/j.resmic.2005.01.011

72. Hou L, Zheng Y, Liu M, Li X, Lin X, Yin G, Gao J, Deng F, Chen F, Jiang X (2015) Anaerobic ammonium oxidation and its contribution to nitrogen removal in China's coastal wetlands. Sci Rep 5:15621. doi:10.1038/srep15621

73. Dang H, Zhou H, Zhang Z, Yu Z, Hua E, Liu X, Jiao N (2013) Molecular detection of Candidatus Scalindua pacifica and environmental responses of sediment anammox bacterial community in the Bohai Sea, China. PloS One 8:e61330-e61330. doi:10.1371/journal.pone.0061330

74. Shehzad A, Liu J, Yu M, Qismat S, Liu J, Zhang X (2016) Diversity, community composition and abundance of anammox bacteria in sediments of the north marginal seas of China. Microbes Environ 31:111-120. doi:10.1264/jsme2.ME15140

75. Kuypers MMM (2017) A fight for scraps of ammonia. Nature 549:162-163. doi:10.1038/549162a

76. He H, Zhen Y, Mi T, Fu L, Yu Z (2018) Ammonia-oxidizing archaea and bacteria differentially contribute to ammonia oxidation in sediments from adjacent waters of Rushan Bay, China. Front Microbiol 9:116. doi:10.3389/fmicb.2018.00116

\section{Tables}


Table 1 Primers for PCR amplification of amoA and $h z s B$ gene fragments

\begin{tabular}{|c|c|c|c|c|c|}
\hline Primer & Sequence $\left(5^{\prime}-3^{\prime}\right)$ & $\begin{array}{l}\text { Length } \\
\text { (bp) }\end{array}$ & $\begin{array}{l}\text { Anneal. } \\
\text { Temp. }\left({ }^{\circ} \mathrm{C}\right)\end{array}$ & Operation & Reference \\
\hline \multicolumn{6}{|l|}{ AOA $a m o A$} \\
\hline $\begin{array}{l}\text { ArchamoA } \\
23 \mathrm{~F}\end{array}$ & ATGGTCTGGYTWAGACG & \multirow[t]{2}{*}{624} & \multirow[t]{2}{*}{58} & \multirow[t]{2}{*}{ PCR } & \multirow[t]{2}{*}{ [14] } \\
\hline $\begin{array}{l}\text { ArchamoA } \\
616 \mathrm{R}\end{array}$ & GCCATCCABCKRTANGTCCA & & & & \\
\hline amo196F & GGWGTKCCRGGRACWGCMAC & \multirow[t]{2}{*}{103} & \multirow[t]{2}{*}{55} & \multirow[t]{2}{*}{ qPCR } & \multirow[t]{2}{*}{ [16] } \\
\hline amo277R & CRATGAAGTCRTAHGGRTADCC & & & & \\
\hline \multicolumn{6}{|c|}{ ParAOB amoA } \\
\hline $\begin{array}{l}\text { BacamoA } \\
1 \mathrm{~F}\end{array}$ & GGGGTTTCTACTGGTGGT & \multirow[t]{2}{*}{491} & \multirow[t]{2}{*}{60} & \multirow[t]{2}{*}{$\begin{array}{l}\text { PCR, } \\
\text { qPCR }\end{array}$} & \multirow[t]{2}{*}{ [15] } \\
\hline $\begin{array}{l}\text { BacamoA } \\
2 \mathrm{R}\end{array}$ & СCCCTCKGSAAAGCCTTCTTC & & & & \\
\hline \multicolumn{6}{|c|}{ ComAOB amoA } \\
\hline comamoA F & AGGNGAYTGGGAYTTCTGG & \multirow[t]{2}{*}{436} & \multirow[t]{2}{*}{62} & \multirow{2}{*}{$\begin{array}{l}\text { PCR, } \\
\text { qPCR }\end{array}$} & \multirow[t]{2}{*}{ [30] } \\
\hline $\begin{array}{l}\text { comamoA } \\
\mathrm{R}\end{array}$ & CGGACAWABRTGAABCCCAT & & & & \\
\hline \multicolumn{6}{|l|}{$\begin{array}{l}\text { AnAOB } \\
h z s B\end{array}$} \\
\hline hzsB364f- & AGCTGGAAGAAYRYRAAGTAYAT & \multirow[t]{2}{*}{450} & \multirow[t]{2}{*}{55} & \multirow{2}{*}{$\begin{array}{l}\text { PCR, } \\
\text { qPCR }\end{array}$} & \multirow[t]{2}{*}{ [36] } \\
\hline hzsB790r & CCSGTYCCHACRTCATGVGTCTG & & & & \\
\hline
\end{tabular}

\section{Figures}


A
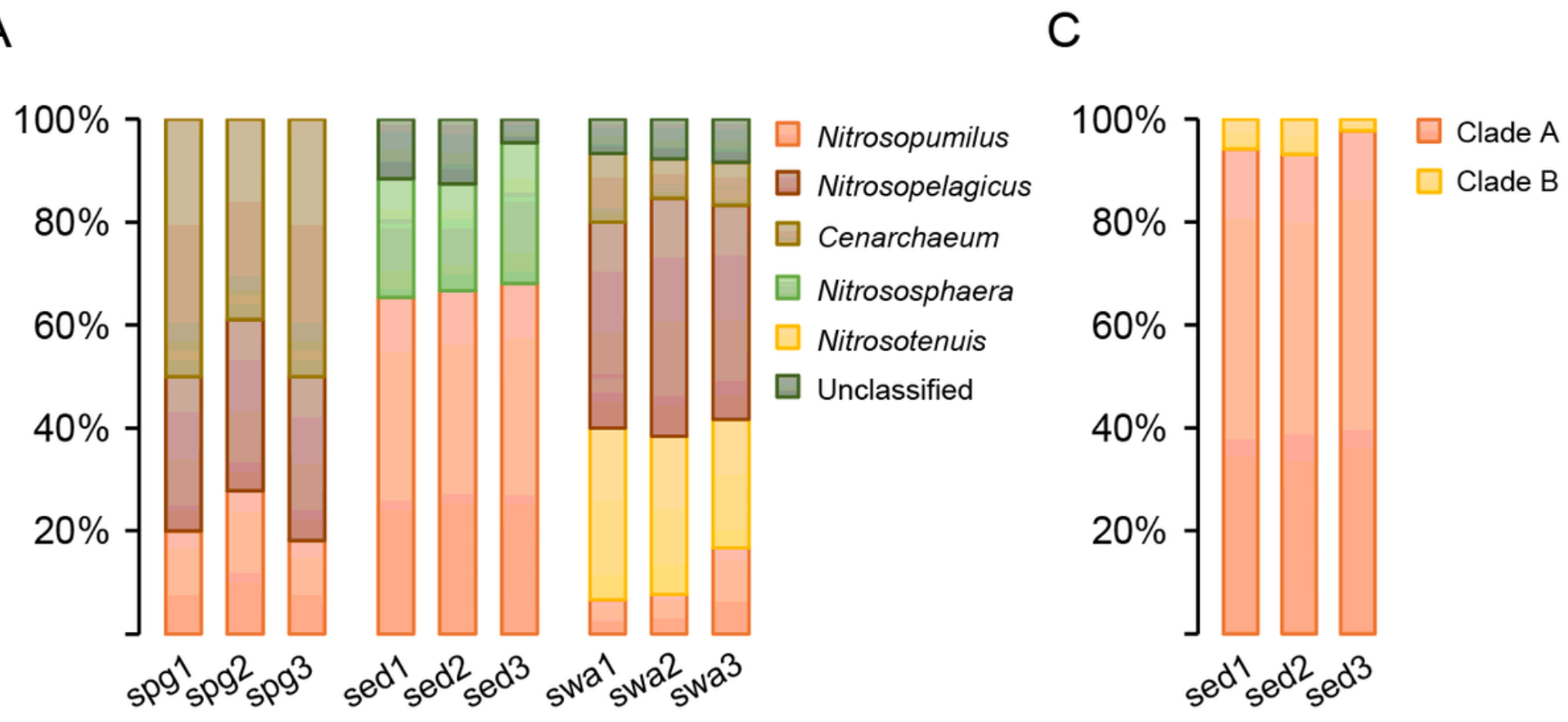

B

D

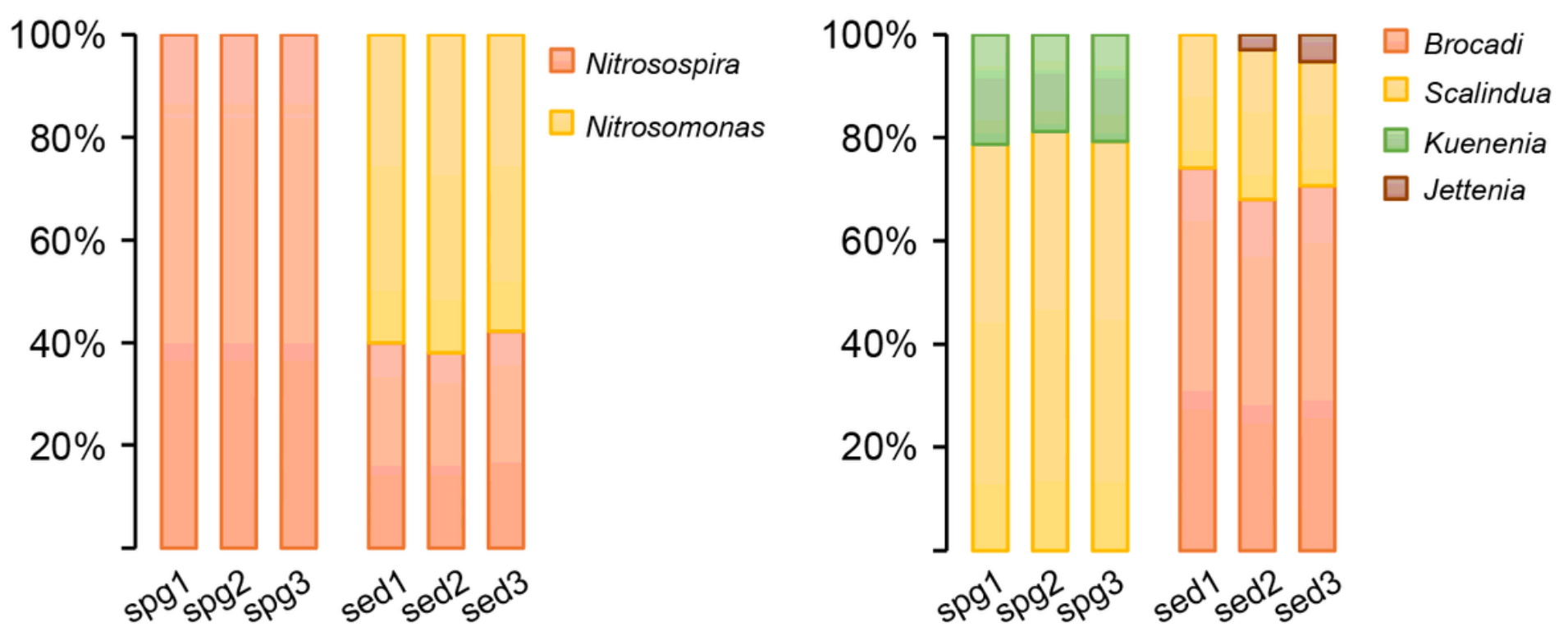

Figure 1

Population composition of $A O A$, parAOB, ComAOB, and $A n A O B$ in C. australiensis, seawater and sediment niches based on the taxonomic classification of amoA and hzsB transcript sequences. 
A

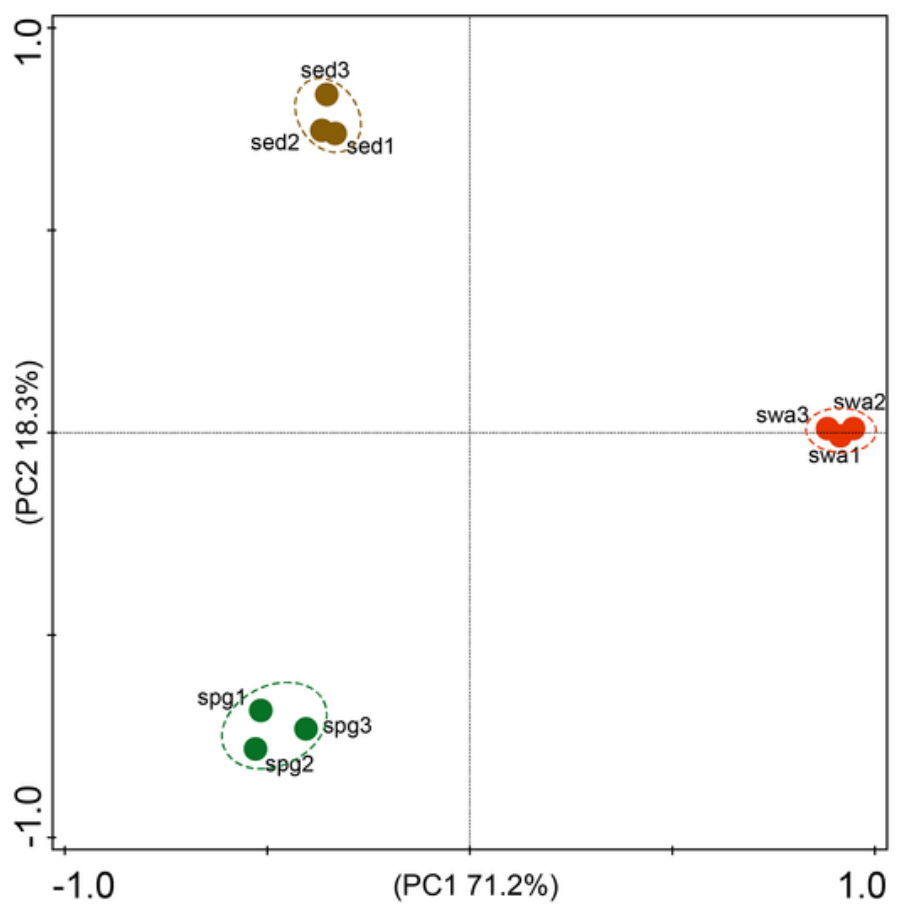

C

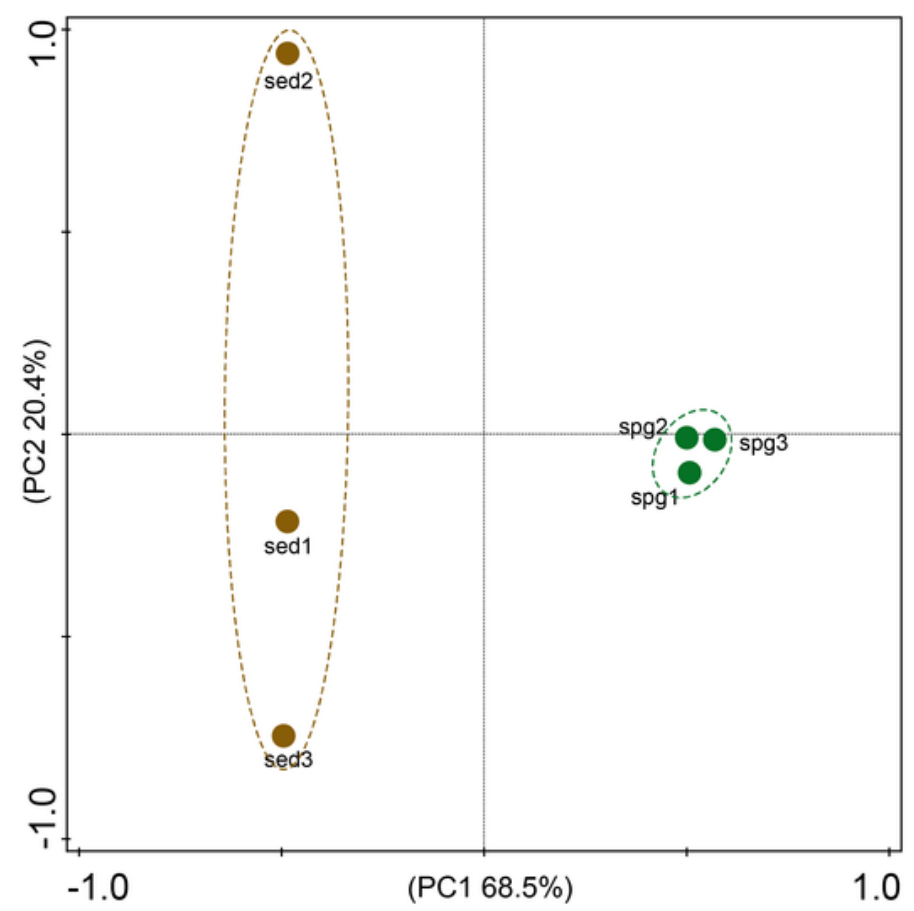

Figure 2

PCoA of the $A O A(A)$, parAOB (B), and AnAOB (C) populations based on the amoA or hzsB transcript phylotypes retrieved from $C$. australiensis, seawater and sediment niches from three sampling sites. 

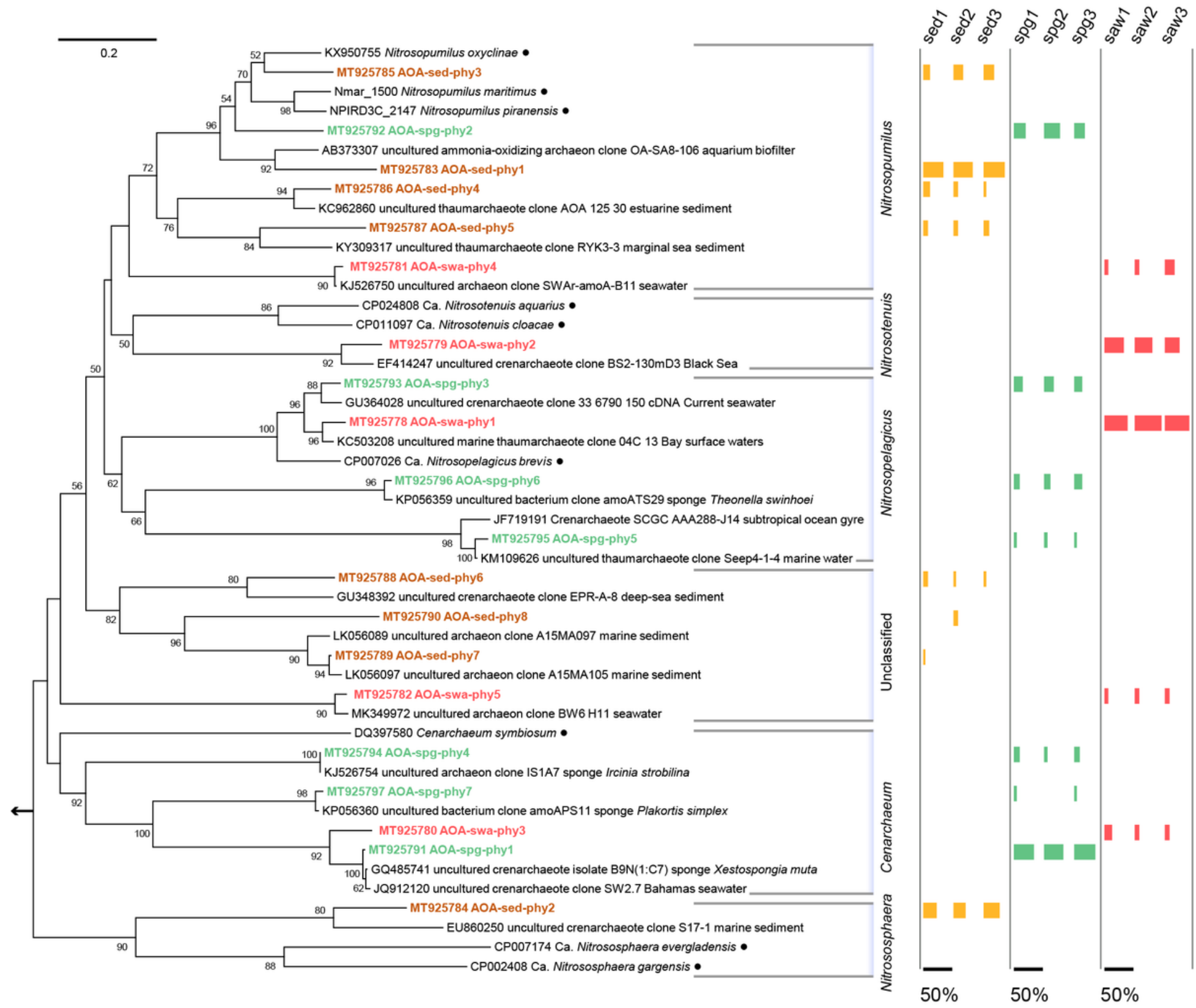

\section{Figure 3}

Phylogenetic maximum-likelihood tree of AOA amoA transcript phylotypes retrieved from the sponge C. australiensis, ambient seawater, and sediment niches. Scale bar represents $20 \%$ sequence divergence per homologous position. Bootstrap values more than 50\% of 1000 replicates are shown. Phylotypes retrieved from $\mathrm{C}$. australiensis, seawater and sediment niches were marked with purple, blue, red, and yellow, respectively. The outgroup symbolized by an arrow represented the amoA sequence of Nitrosomonas europaea ATCC 19178 (JN099309). AOA, ammonia-oxidizing archaea 

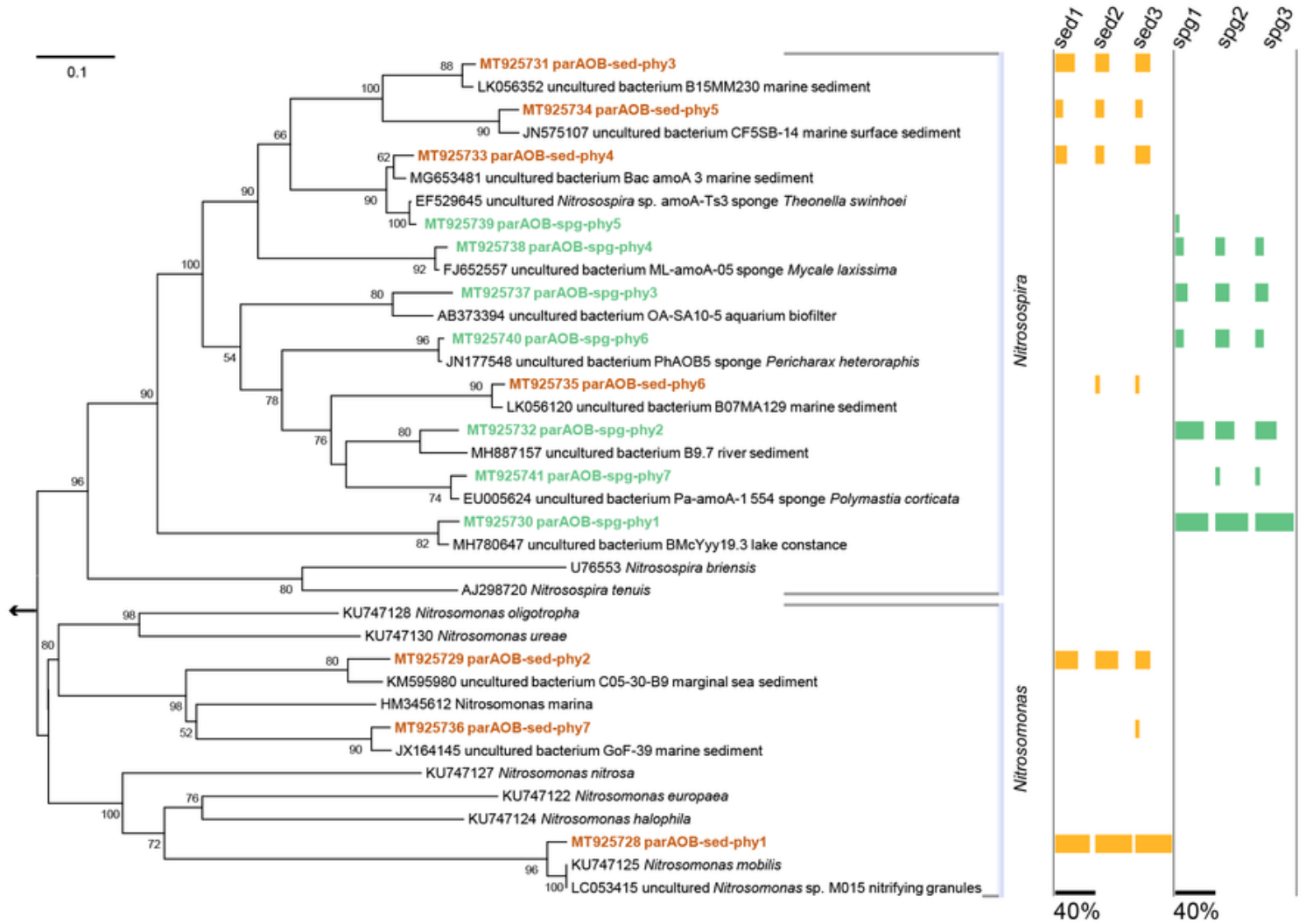

B
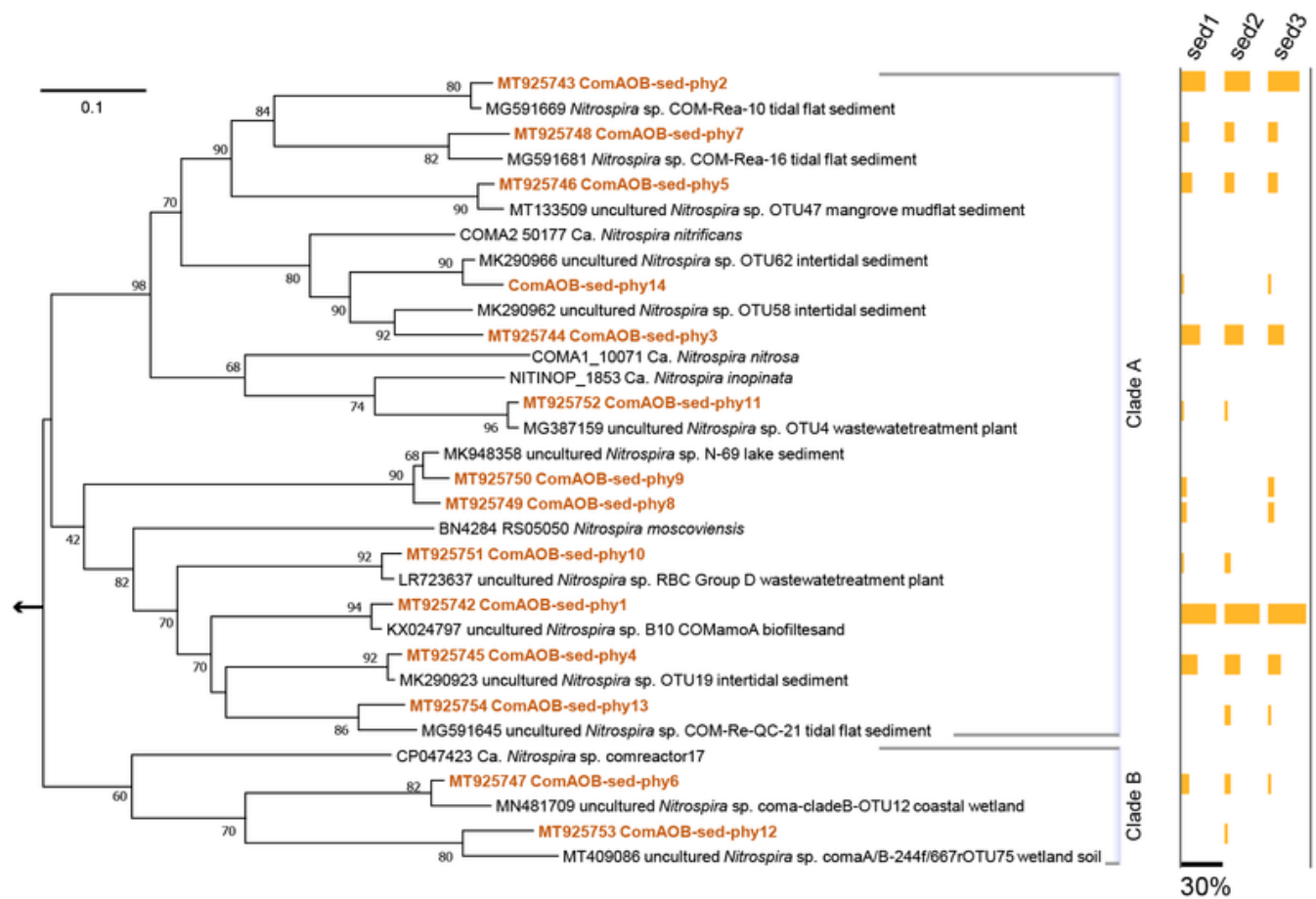

Figure 4

Phylogenetic maximum-likelihood tree of parAOB amoA (A) and comAOB amoA (B) transcript phylotypes retrieved from the sponge $C$. australiensis, ambient seawater, and sediment niches. Scale bar represents $10 \%$ sequence divergence per homologous position. Bootstrap values more than $50 \%$ of 1000 replicates are shown. Phylotypes retrieved from $\mathrm{C}$. australiensis, and sediment niches were marked with blue and yellow, respectively. The outgroup symbolized by an arrow represented the amoA sequence of Ca. 
Nitrosocosmicus arcticus (MK978767) (A) or by an arrow represented the pmoA sequence of Crenothrix polyspora (DQ295902) (B). parAOB, partial-nitrification ammonia-oxidizing bacteria; comAOB, completenitrification ammonia-oxidizing bacteria

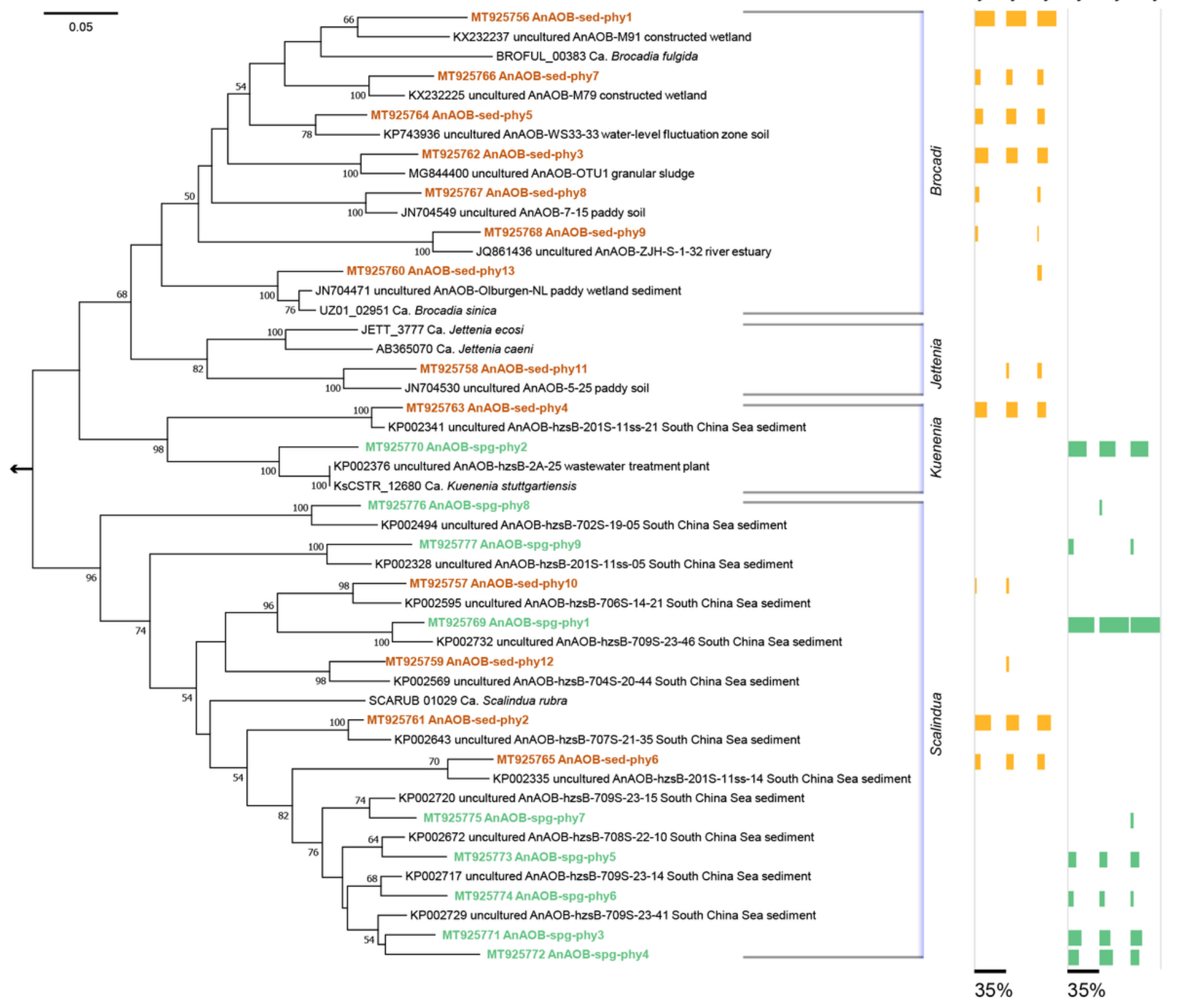

\section{Figure 5}

Phylogenetic maximum-likelihood tree of AnAOB hzsB transcript phylotypes retrieved from the sponge C. australiensis, ambient seawater, and sediment niches. Scale bar represents $5 \%$ sequence divergence per homologous position. Bootstrap values more than $50 \%$ of 1000 replicates are shown. Phylotypes retrieved from $\mathrm{C}$. australiensis, seawater and sediment niches were marked with blue and yellow, respectively. The outgroup symbolized by an arrow represented the hzsB sequence of Planctomycetes bacterium (A3D13_04020). AnAOB, anaerobic ammonia-oxidizing bacteria 


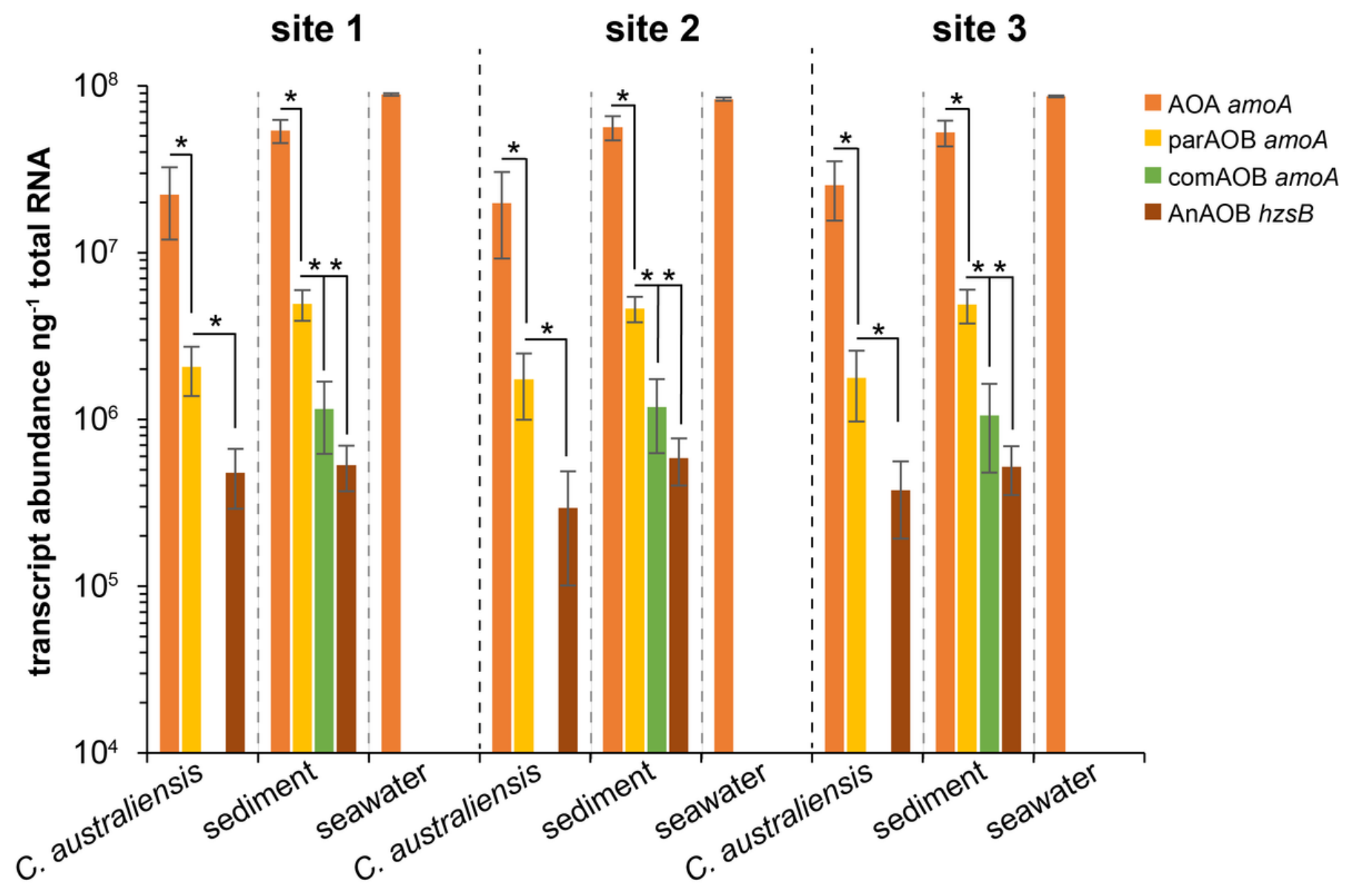

Figure 6

Abundance of transcribed amoA and hzsB genes estimated by qPCR for the sponge $\mathrm{C}$. australiensis, seawater and sediment niches. The depicted values are the means of sample triplicates and technical triplicates in each site, and the error bars indicate the standard error. The * symbol indicated the significant difference of transcript abundance $(p<0.05)$

\section{Supplementary Files}

This is a list of supplementary files associated with this preprint. Click to download.

- Graphicabstract.tif

- Supplementaryinformation.docx 